\title{
Association between Protective Efficacy of Antibodies to Tumor Necrosis Factor and Suppression of Nitric Oxide Production in Neonatal Rats with Fatal Infection
}

\author{
YUAN SHI, HUA-QIANG LI, CHI-KAO SHEN, JIANG-HUAI WANG, JIE PAN, \\ SHI-WEN QIN, AND REN LIU \\ Department of Pediatrics, Daping Hospital, and Institute of Surgery, Third Military Medical University, \\ Chongqing, Sichuan Province, 630042, China
}

\begin{abstract}
In a rat model of fatal infection caused by Pseudomonas aeruginosa, the circulating level of nitrite/ nitrate $\left(\mathrm{NO}_{2}^{-} / \mathrm{NO}_{3}^{-}\right)$, a good indicator for nitric oxide production, was remarkably increased after elevation of circulatory tumor necrosis factor (TNF). Anti-TNF MAb cotreatment was shown to blunt hypoglycemia and hyperlacticemia and was associated with decreased mortality of septic animals. Moreover, anti-TNF MAb significantly reduced not only plasma TNF but also plasma $\mathrm{NO}_{2}{ }^{-} / \mathrm{NO}_{3}{ }^{-}$ levels. Dexamethasone had a similar effects, and when anti-TNF MAb was used in combination with dexamethasone, the suppression of nitric oxide production and the protective efficacy were more remarkable compared with therapy with either anti-TNF MAb or dexamethasone alone. Our present data suggested that the protective efficacy of anti-TNF MAb may correlate with the suppression of nitric oxide production and also with a modulation in metabolic abnormalities in the septic newborn rats. (Pediatr Res 34: 345-348, 1993)
\end{abstract}

\section{Abbreviations}

NO, nitric oxide

$\mathrm{NO}_{2}^{-} / \mathrm{NO}_{3}^{-}$, nitrite/nitrate

TNF, tumor necrosis factor

L-NMMA, $\mathbf{N}^{\mathrm{G}}$-monomethyl-L-arginine

The cytokine TNF plays a pivotal role in the pathophysiologic consequences of severe infection and is an important mediator of fatal septic shock. Infusion of recombinant TNF induces cardiovascular shock and metabolic derangements similar to both experimental and clinical septic shock. Antibodies to TNF have been confirmed to protect a few kinds of animals from septic death (1). Moreover, elevated circulatory TNF levels correlate with lethal outcome in critically ill patients with sepsis as well as septic shock (2). However, there have been few studies that deal with efficacy of antibodies to TNF in newborns with serious infection.

Recently, NO, a freely diffusible free radical that decomposes spontaneously to $\mathrm{NO}_{2}^{-} / \mathrm{NO}_{3}^{-}$, has also been implicated in the pathogenesis of severe infection, especially septic shock (3). TNF as well as endotoxin can enhance endogenous synthesis of NO by induction of an NO synthase in endothelial and monocyte-

Received January 19, 1993; accepted April 22, 1993.

Correspondence: Yuan Shi, MS, Department of Pediatrics, Daping Hospital, Third Military Medical University, Chongqing, Sichuan Province, 630042. China. macrophage cells. This inducible enzyme differs from the constitutive isoform found in endothelial as well as other cell types and is now believed to be responsible for the sustained vasodilatation and hypotension that characterize septic shock (4). Indeed, the hypotension induced by TNF can be completely reversed after administration of $\mathrm{N}^{\mathrm{G}}$-monomethyl-L-arginine (L-NMMA), an L-arginine analogue that inhibits NO synthase (5). The aim of our present study was to investigate whether NO is increased in neonatal rats suffering from fatal infection and, if so, whether anti-TNF MAb would interfere with NO production and whether circulating $\mathrm{NO}_{2}{ }^{-} / \mathrm{NO}_{3}{ }^{-}$levels would correlate with the protective efficacy of these antibodies.

\section{MATERIALS AND METHODS}

Animals. Ten-d-old newborn Wistar rats (18 to $24 \mathrm{~g}$ ) were used. All rats were born at our facility and remained with their dam until the 10th day of life. On d 10, the rats were removed from the dams and fasted for $4 \mathrm{~h}$ in a controlled temperature environment without access to water.

Organism. A gentamicin-susceptible strain of $P$. aeruginosa from a clinical isolate (belonging to Fisher-Devlin-Gnabasik immunotype IV) was used to infect the animals. The organisms were stored in $10 \%$ glycerin at $-70^{\circ} \mathrm{C}$ until ready for use. The day before challenge, the isolate was streaked on trypticase soy agar and incubated overnight at $37^{\circ} \mathrm{C}$. The next day, the bacteria were suspended in sterile normal saline and adjusted spectrophotometrically to a predetermined inoculum size of $10^{11}$ organisms/ $\mathrm{mL}$.

In our laboratory, an inoculum of $10^{9}$ live $P$. aeruginosa/g body weight was a $90 \%$ lethal dose within $24 \mathrm{~h}$ in 10 -d-old rats when gentamicin was initiated $(5 \mathrm{mg} / \mathrm{kg}$, twice a day) $2 \mathrm{~h}$ after the bacterial challenge. This dose of $P$. aeruginosa and gentamicin was used in all subsequent experiments, and the bacteria were injected s.c. into the dorsum after the skin was washed with $75 \%$ alcohol.

Anti-TNF MAb preparation. The murine-derived anti-recombinant human TNF MAb (designated $Z 8$ ), which has been shown to have similar neutralization of recombinant human TNF and rat TNF, was prepared and provided by the Institute of Military Medical Sciences of PLA (Beijing, China). The IgGl anti-TNF $\mathrm{MAb}$ was free of endotoxin $(<0.05 \mu \mathrm{g} / \mathrm{mg}$ of protein) as determined by the Limulus lysate gelation assay.

Experimental Design. P. aeruginosa challenge. Thirty-five newborn rats were individually injected with the bacteria as well as gentamicin, as mentioned above. Then, at the designed time point $(0,2,4,6,8,10$, and $12 \mathrm{~h}$ postinjection), five newborn rats were killed and the central blood samples were collected in heparinized tubes. Blood samples were immediately centrifuged, 
and plasma samples were stored at $-70^{\circ} \mathrm{C}$ until assay for TNF, glucose, and lactic acid, except the blood samples for assay of $\mathrm{NO}_{2}{ }^{-} / \mathrm{NO}_{3}{ }^{-}$, which were protein-precipitated $\left(30 \% \mathrm{ZnSO}_{4}, 0.05\right.$ $\mathrm{mL} / \mathrm{mL}$ of blood) before centrifugation. Blood cultures were also performed aseptically.

Anti-TNF MAb or/and dexamethasone cotreatment. Ten-dold rats were divided into four groups $(n=22)$ and received intraperitoneal injections in addition to the bacteria and gentamicin mentioned above as follows: group 1, $0.1 \mathrm{~mL}$ of saline; group 2, $0.1 \mathrm{~mL}$ of anti-TNF MAb $(\mathrm{Z} 8,5 \mathrm{mg} / \mathrm{kg})$; group $3,0.1$ $\mathrm{mL}$ of dexamethasone $(5 \mathrm{mg} / \mathrm{kg})$; and group $4,0.1 \mathrm{~mL}$ of antiTNF MAb $(Z 8,5 \mathrm{mg} / \mathrm{kg})$ in combination with dexamethasone $(5 \mathrm{mg} / \mathrm{kg})$. At 6 and $12 \mathrm{~h}$ postinjection, five newborn rats in each group were killed, and the central blood was collected for assay. The other 12 neonatal rats in each group served as observed subjects for the count of 24-h mortality. Necropsy cultures were obtained from the newborn rats who died and from those surviving animals killed at $24 \mathrm{~h}$, the end of the experiment.

Assays. Assay of $\mathrm{NO}_{2}^{-} / \mathrm{NO}_{3}^{-}$levels. $\mathrm{NO}_{2}^{-} / \mathrm{NO}_{3}^{-}$level has been confirmed to be a good indicator for NO production (6). The method described by Hegesh and Shiloah (7) was used with slight modifications. One $\mathrm{mL}$ of plasma sample was passed through a cadmium reduction column $(100 \times 8 \mathrm{~mm})$ pre-washed with distilled water, $0.1 \mathrm{~mol} / \mathrm{L} \mathrm{HCl}$, distilled water, and ammonium hydroxide buffer $(0.1 \mathrm{~mol} / \mathrm{L}, \mathrm{pH} 9.6), 5 \mathrm{~mL}$ of each. Passing through the column, nitrate is quantitatively reduced to nitrite. After application of the sample, the column was eluted with a $3.42 \mathrm{~mol} / \mathrm{L} \mathrm{NaCl}$ solution in $0.05 \mathrm{~mol} / \mathrm{L}, \mathrm{pH} \mathrm{9.6,} \mathrm{ammonium}$ chloride buffer. One $5.0-\mathrm{mL}$ fraction of the effluent was collected immediately after the application, and to it, $0.5 \mathrm{~mL}$ of a 29.0 $\mathrm{mmol} / \mathrm{L}$ sulfanilamide solution in $6.4 \mathrm{~mol} / \mathrm{L} \mathrm{HCl}$ was added. The tube was mixed, and $3 \mathrm{~min}$ later $0.2 \mathrm{~mL}$ of $19.3 \mathrm{mmol} / \mathrm{L}$ $\mathrm{N}$-(1-naphthyl)ethylenediamine dihydrochloride was added. Absorbance of the pink color was measured after $20 \mathrm{~min}$ at 540 $\mathrm{nm}$. More than $90 \%$ of the nitrite was found in the $5-\mathrm{mL}$ fraction. Dilutions of sodium nitrite were used to prepare a standard curve. We did not attempt to differentiate between $\mathrm{NO}_{2}^{-}$and $\mathrm{NO}_{3}{ }^{-}$amounts, inasmuch as very little $\mathrm{NO}_{2}{ }^{-}$was found in the circulation (7).

Detection of TNF levels. The bioassay for TNF using the $\mathrm{L}$ 929 cell line has been described elsewhere (8). In our laboratory, $1 \mathrm{U}$. corresponded to $1.67 \mathrm{pg}$ recombinant murine TNF (Genzyme Corporation, Cambridge, MA).

Assay for glucose and lactic acid concentrations. Blood samples were processed for glucose and lactic acid by routine methods (9).

Statistical analysis. The $\chi^{2}$ test or $t$ test, Wilcoxon two-sample test, and, when more than two groups were involved, KruskalWallis test, and the Spearman rank-correlation coefficient were used. All data were presented as mean $\pm \mathrm{SD}$, unless specified otherwise. Significance was accepted at $p<0.05$.

\section{RESULTS}

$P$. aeruginosa challenge. Blood cultures performed at 0,2 , and $4 \mathrm{~h}$ postchallenge revealed none positive for $P$. aeruginosa. However, blood cultures obtained at 6,8 , and $10 \mathrm{~h}$ revealed documented bacteremia in $40 \%$ of the killed animals, and the incidence of the bacteremia reached $80 \%$ at $12 \mathrm{~h}$.

Figure 1 depicts the time course of plasma $\mathrm{NO}_{2}^{-} / \mathrm{NO}_{3}{ }^{-}$changes in the challenge test. The fatal infection in newborn rats caused a gradual rise of plasma $\mathrm{NO}_{2}{ }^{-} / \mathrm{NO}_{3}{ }^{-}$to rather high levels. The plasma $\mathrm{NO}_{2}{ }^{-} / \mathrm{NO}_{3}{ }^{-}$levels were significantly elevated by $6 \mathrm{~h}$ and peaked at $12 \mathrm{~h}$ postchallenge.

The time course of changes in plasma TNF levels of the septic newborn rats is summarized in Figure 2. The plasma TNF levels rose rapidly to a peak at $6 \mathrm{~h}$ and then gradually declined to very low levels.

The $90 \%$ lethal dose of $P$. aeruginosa challenge in the newborn rats induced metabolic derangements, that is, the changes of circulating levels of glucose and lactic acid. The basal levels of lactic acid were $1.56 \pm 0.34 \mathrm{mmol} / \mathrm{L}$ at $0 \mathrm{~h}$, and hyperlacticemia developed continuously with markedly elevated levels at $8 \mathrm{~h}$ $(2.88 \pm 0.27 \mathrm{mmol} / \mathrm{L} ; p<0.05)$ and the peak levels at $12 \mathrm{~h}(6.01$ $\pm 0.54 \mathrm{mmol} / \mathrm{L} ; p<0.05$ compared with those at 0 and $8 \mathrm{~h}$ ). The basal levels of glucose were $5.34 \pm 0.81 \mathrm{mmol} / \mathrm{L}$ at $0 \mathrm{~h}$. After the challenge, the animals experienced abrupt hyperglycemia of $8.07 \pm 0.89 \mathrm{mmol} / \mathrm{L}$ at $6 \mathrm{~h}(p<0.05)$ followed by hypoglycemia beginning at $8 \mathrm{~h}(4.16 \pm 1.15 \mathrm{mmol} / \mathrm{L} ; p<0.05$ compared with those at $0 \mathrm{~h}$ ) and developing to the most severe point at $12 \mathrm{~h}(1.47 \pm 0.72 \mathrm{mmol} / \mathrm{L} ; p<0.05$ compared with those at 0 and $8 \mathrm{~h}$ ).

Anti-TNF MAb or/and dexamethasone cotreatment. There were no significant differences $(p>0.05)$ among the incidence of positive blood cultures for $P$. aeruginosa in the four experimental groups (40\% in control or dexamethasone group, $20 \%$ in anti-TNF MAb or combined-cotreatment group at $6 \mathrm{~h} ; 60 \%$ in all four groups at $12 \mathrm{~h}$ ). Necropsy of the animals that died during the experimental course all revealed documented bacteremia, whereas necropsy of the surviving rats killed at the end of the experiment revealed bacteremia in $67 \%$ of the anti-TNF MAb group, $83 \%$ of the dexamethasone group, and $55 \%$ of the combined cotreatment group. The only animal that survived in the control group was bacteremic when killed at $24 \mathrm{~h}$.

Cotreatment with anti-TNF MAb or dexamethasone was found to not only decrease the plasma TNF levels but also attenuate the plasma $\mathrm{NO}_{2}^{-} / \mathrm{NO}_{3}{ }^{-}$levels statistically. Moreover, when anti-TNF MAb was used in combination with dexamethasone, the suppression of TNF and $\mathrm{NO}_{2}{ }^{-} / \mathrm{NO}_{3}{ }^{-}$concentrations in the circulation was even more remarkable compared with that when using anti-TNF MAb or dexamethasone alone (Table 1).

The metabolic derangements of the septic newborn rats were markedly improved after administration of anti-TNF or MAb or/and dexamethasone. The levels of circulating lactic acid in the anti-TNF MAb group (at $6 \mathrm{~h}, 1.93 \pm 0.05 \mathrm{mmol} / \mathrm{L}$; at $12 \mathrm{~h}$, $3.54 \pm 0.62 \mathrm{mmol} / \mathrm{L}$ ) and in the dexamethasone group (at $6 \mathrm{~h}$, $1.93 \pm 0.11 \mathrm{mmol} / \mathrm{L} ;$ at $12 \mathrm{~h}, 3.19 \pm 0.09 \mathrm{mmol} / \mathrm{L}$ ) were significantly lower than those in the controls (at $6 \mathrm{~h}, 2.03 \pm 0.05$ $\mathrm{mmol} / \mathrm{L}$; at $12 \mathrm{~h}, 5.58 \pm 0.43 \mathrm{mmol} / \mathrm{L} ; p<0.05)$. The hyperlacticemia was most improved in the combined cotreatment group (at $6 \mathrm{~h}, 1.78 \pm 0.11 \mathrm{mmol} / \mathrm{L} ;$ at $12 \mathrm{~h}, 1.87 \pm 0.51 \mathrm{mmol} / \mathrm{L} ; p<$ 0.05 compared with the other groups). Similarly, hypoglycemia at $12 \mathrm{~h}$ in the controls $(1.60 \pm 0.43 \mathrm{mmol} / \mathrm{L})$ was significantly reversed by anti-TNF MAb $(2.25 \pm 0.25 \mathrm{mmol} / \mathrm{L})$ and dexamethasone $(2.39 \pm 0.44 \mathrm{mmol} / \mathrm{L})(\vec{p}<0.05)$. Administration of anti-TNF MAb in combination with dexamethasone caused the most significant improvement of hypoglycemia at $12 \mathrm{~h}(2.95 \pm$ $0.07 \mathrm{mmol} / \mathrm{L} ; p<0.05$ compared with the other three groups).

As shown in Table 2, anti-TNF MAb remarkedly decreased mortality in the neonatal rat model of $P$. aeruginosa infection, and dexamethasone had a similar effect. Furthermore, the two combined produced additional benefits.

\section{DISCUSSION}

Our present study demonstrated that NO production was significantly increased in neonatal rats with fatal infection caused by $P$. aeruginosa. Circulating $\mathrm{NO}_{2}^{-} / \mathrm{NO}_{3}{ }^{-}$, appearing slightly later than TNF, was statistically detectable by $6 \mathrm{~h}$ and peaked 12 $h$ postchallenge. In adult animal models, endotoxin and toxic shock syndrome toxin 1 have been shown to increase NO production $(6,10)$. Ochoa et al. (11) first reported elevated plasma levels of $\mathrm{NO}_{2}^{-} / \mathrm{NO}_{3}{ }^{-}$in human adults suffering from sepsis. Moreover, in a very recent study, we found highly elevated circulating nitrogen oxide during the course of human neonatal sepsis and its association with the occurrence of septic shock (unpublished observations).

TNF has been described to enhance NO production in vitro (4). In our study, in newborn rats that received anti-TNF MAb injections, not only plasma TNF levels but also plasma $\mathrm{NO}_{2}^{-}$/ 


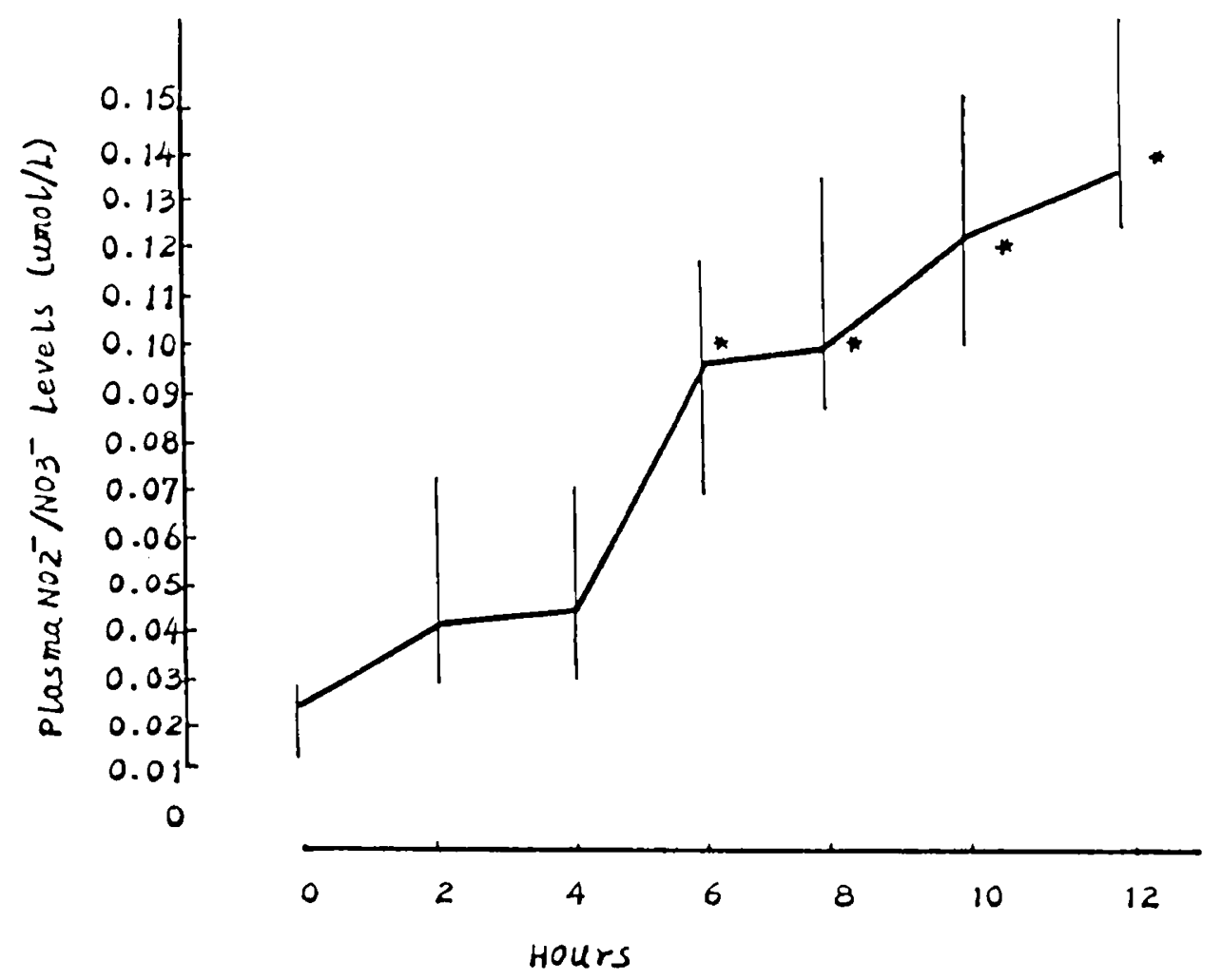

Fig. 1. The time course of plasma $\mathrm{NO}_{2}{ }^{-} / \mathrm{NO}_{3}{ }^{-}$levels after s.c. challenge with a $90 \%$ lethal dose of $P$. aeruginosa as well as gentamicin. All data are medians, with range by a vertical line. ${ }^{*}, p<0.05$ compared with $0 \mathrm{~h}$.

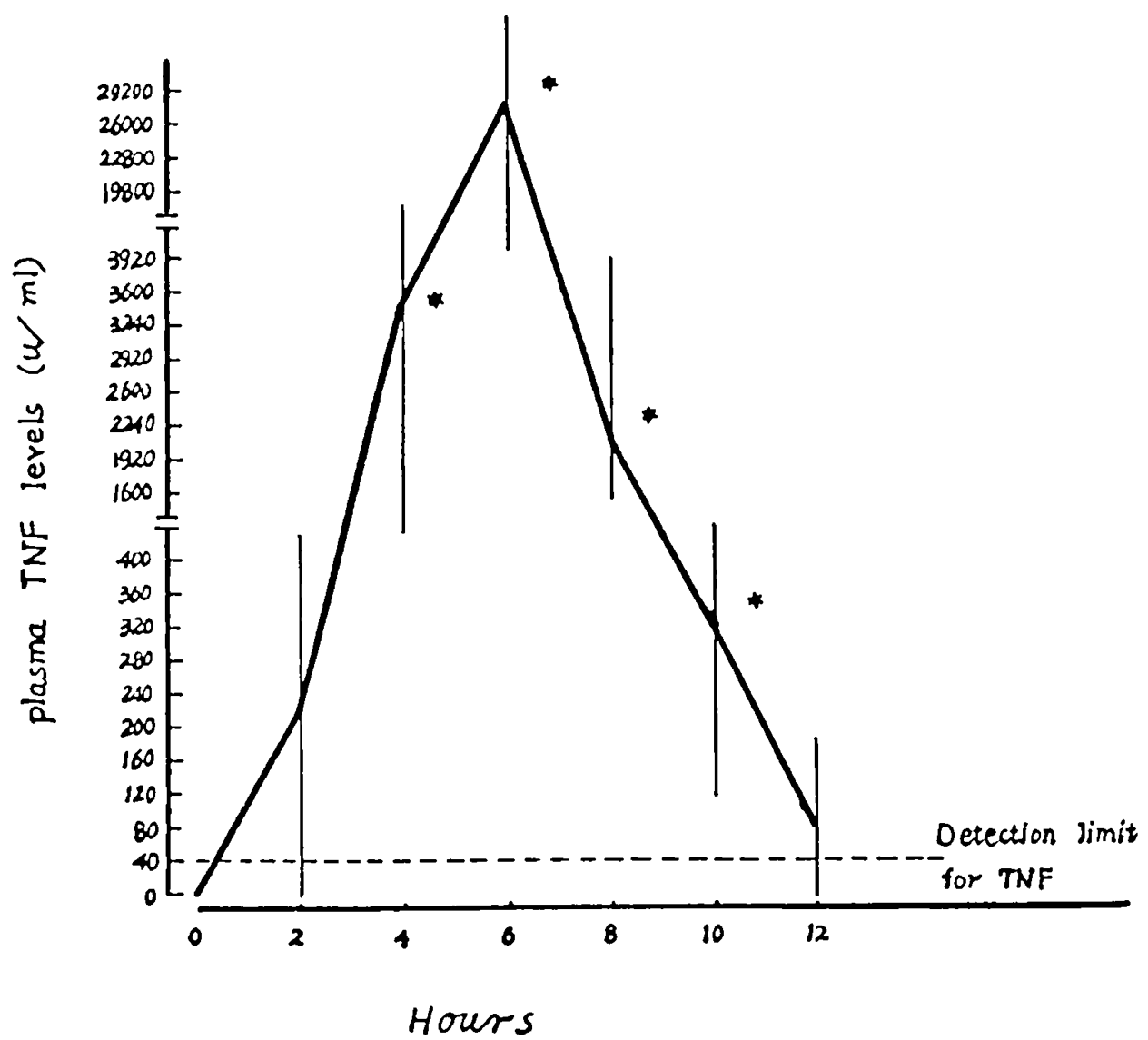

Fig. 2. The time course of plasma TNF levels after s.c. challenge with a $90 \%$ lethal dose of $P$. aeruginosa as well as gentamicin. All data are medians, with range shown by a vertical line. ${ }^{*}, p<0.05$ compared with $0 \mathrm{~h}$. 
Table 1. Comparison of circulating $\mathrm{NO}_{2}^{-} / \mathrm{NO}_{3}{ }^{-}$and TNF levels after different therapeutic agents ${ }^{*}$

\begin{tabular}{|c|c|c|c|c|}
\hline \multirow[b]{2}{*}{ Group } & \multicolumn{2}{|c|}{$6 \mathrm{~h}$} & \multicolumn{2}{|c|}{$12 \mathrm{~h}$} \\
\hline & $\begin{array}{c}\mathrm{NO}_{2}^{-} / \mathrm{NO}_{3}^{-} \\
(\mu \mathrm{mol} / \mathrm{L})\end{array}$ & $\begin{array}{c}\text { TNF } \\
(\mathrm{U} / \mathrm{mL})\end{array}$ & $\begin{array}{c}\mathrm{NO}_{2}{ }^{-} / \mathrm{NO}_{3}{ }^{-} \\
(\mu \mathrm{mol} / \mathrm{L})\end{array}$ & $\begin{array}{c}\text { TNF } \\
(\mathrm{U} / \mathrm{mL})\end{array}$ \\
\hline Control & $0.093 \pm 0.029$ & $19456.0 \pm 11675.4$ & $0.134 \pm 0.040$ & $112.0 \pm 33.5$ \\
\hline Anti-TNF MAb & $0.042 \pm 0.019 \dagger$ & $1600.0 \pm 640.0 \dagger$ & $0.086 \pm 0.019 \dagger$ & $\mathrm{ND} \dagger$ \\
\hline Dexamethasone & $0.056 \pm 0.016$ & $2497.0 \pm 2965.5 \dagger$ & $0.095 \pm 0.017 \dagger$ & $\mathrm{ND} \dagger$ \\
\hline Anti-TNF MAb and dexamethasone & $0.038 \pm 0.015 \dagger$ & $576.0 \pm 87.6 \dagger \ddagger$ & $0.061 \pm 0.022 \dagger \ddagger$ & $\mathrm{ND} \dagger$ \\
\hline
\end{tabular}

* All data are mean \pm SD. ND, not detectable.

$\dagger p<0.05$ compared with control group.

$\ddagger p<0.05$ compared with anti-TNF MAb or dexamethasone group.

Table 2. Twenty-four-h mortality in 10-d-old rats

\begin{tabular}{lc}
\hline \multicolumn{1}{c}{ Group } & $\begin{array}{c}24 \text {-h mortality } \\
\text { rate }(\%)\end{array}$ \\
\hline Control & $92(11 / 12)$ \\
Anti-TNF MAb & $50(6 / 12)^{*}$ \\
Dexamethasone & $50(6 / 12)^{*}$ \\
Anti-TNF MAb and dexamethasone & $8(1 / 12)^{*} \dagger$ \\
\hline
\end{tabular}

$* p<0.05$ compared with control group.

$\dagger p<0.05$ compared with anti-TNF MAb or dexamethasone group.

$\mathrm{NO}_{3}{ }^{-}$concentrations were statistically attenuated. We suggest that TNF secretion, preceding NO production, might be associated with $\mathrm{NO}$ release in vivo.

In the present study, we discovered that anti-TNF MAb therapy altered the time course of hypoglycemia and hyperlacticemia and finally decreased the mortality in 10-d-old septic rats. The protective efficacy of anti-TNF MAb may correlate with the suppression of NO production, and also with the modulation in metabolic abnormalities. We suggest that the suppression of NO production might be at least partly responsible for the effects of anti-TNF MAb that protect newborn rats from septic death, because overproduction of NO has been confirmed to lead to profound vasodilation, hypotension, inadequate tissue perfusion, and metabolic dyshomeostasis (3).

Corticosteroids have been reported to prevent the induction of inducible NO synthase without affecting the activity of constitutive enzyme. Prior treatment with dexamethasone could attenuate NO-mediated cytotoxicity in immunologically stimulated endothelial cells and the hypotension produced by endotoxin in vivo $(12,13)$. Our present data showed that dexamethasone had an inhibitory effect on NO production similar to that of anti-TNF MAb; this suppressive action might contribute partly to its protection of the animals from septic death. Moreover, we confirmed, for the first time, that the use of anti-TNF MAb plus dexamethasone further decreased circulating TNF and $\mathrm{NO}_{2}^{-}-$ $\mathrm{NO}_{3}{ }^{-}$levels, improved hypoglycemia and hyperlacticemia, and finally increased the survival rates in the septic newborn rats even compared with the efficacy using either anti-TNF MAb or dexamethasone alone. Considering that corticosteroids have been shown only to inhibit inducible NO synthase but not to suppress the constitutive isoform that has a role in the physiologic control of blood pressure, the therapy by anti-TNF MAb in combination with dexamethasone may have practical value (14).

To summarize, our present study indicated that NO production would be increased in the model of $P$. aeruginosa infection in neonatal rats, and the highly elevated circulating $\mathrm{NO}_{2}^{-} / \mathrm{NO}_{3}^{-}$ level, a good indicator for NO production, could be decreased by anti-TNF MAb therapy with and without steroids. Thus, we suggested that the protective efficacy of anti-TNF MAb may correlate with the suppression of NO production and also with a modulation in metabolic abnormalities in the septic newborn animals.

\section{REFERENCES}

1. Dinarello CA 1991 The proinflammatory cytokines interleukin-1 and tumor necrosis factor and the treatment of the septic shock syndrome. J Infect Dis 163:1177-1184

2. Bone RC 1991 The pathogenesis of sepsis. Ann Intern Med 115:457-469

3. Kilbourn RG, Griffith OW 1992 Overproduction of nitric oxide in cytokinemediated and septic shock. J Natl Cancer Inst 84:827-832

4. Moncada S, Palmer RMJ, Higgs EA 1991 Nitric oxide: physiology, pathophysiology, and pharmacology. Pharmacol Rev 43:109-142

5. Kilbourn RG, Belloni $P 1990$ Endothelial cell production of nitric oxide in response to interferon gamma in combination with tumor necrosis factor, interleukin-1, or endotoxin. J Natl Cancer Inst 82:772-776

6. Stuehr DJ, Marletta MA 1985 Mammalian nitrate biosynthesis: mouse macrophages produce nitrite and nitrate in response to Escherichia coli lipopolysaccharide. Proc Natl Acad Sci USA 82:7738-7742

7. Hegesh E, Shiloah J 1982 Blood nitrates and infantile methemoglobinemia. Clin Chim Acta 125:107-115

8. Tsujimoto M, Yip YK, Vilcek J 1985 Tumor necrosis factor: specific binding and internalization in sensitive and resistant cells. Proc Natl Acad Sci USA 82:7626-7630

9. MacQueen J, Plaut D 1979 Colorimetric microdetermination of plasma lactate Am J Med Tech 45:34-37

10. Zembowicz A, Vane JR 1992 Induction of nitric oxide synthase activity by toxic shock syndrome toxin 1 in a macrophage-monocyte cell line. Proc Nat Acad Sci USA 89:2051-2055

11. Ochoa JB, Udekwu AO, Billiar TR, Curran RD, Cerra FB, Simmons RL, Pietzman AB 1991 Nitrogen oxide levels in patients after trauma and during sepsis. Ann Surg 214:621-626

12. Rees DD, Cellek S, Palmer RMJ, Moncada S 1990 Dexamethasone prevents the induction by endotoxin of a nitric oxide synthase and the associated effects on vascular tone. An insight into endotoxin shock. Biochem Biophys Res Commun 173:541-547

13. Di Rosa M, Radomski M, Carnuccio R, Moncada S 1990 Glucocorticoids inhibit the induction of nitric oxide synthase in macrophages. Biochem Biophys Res Commun 172:1246-1252

14. Wright CE, Rees DD, Moncada S 1992 Protective and pathological roles of nitric oxide in endotoxin shock. 26:48-57 